\title{
Fungos com Potencial Toxigênico em Condimentos
}

Cátia Daiane Scherer (I), Maria de Jesus Alcano (I), Évelin Francine Wigmann (I), Raquel Carine Jahn (I), Marcelo Valle Garcia (I), Vivian Moraes Machado (I), Marina Venturini Copetti (I)

(I) UFSM - Universidade Federal de Santa Maria (Av. Roraima nํ 1000 Cidade Universitária Bairro Camobi Santa Maria - RS)

\section{Resumo}

Os condimentos em sua maioria são oriundos de países de clima tropical, os quais apresentam temperatura e precipitação pluviométrica elevadas, o que influencia a umidade do solo e favorece a multiplicação microbiana. Após sua colheita, os condimentos em geral permanecem próximo ao solo, em temperatura ambiente para secagem e o que pode predispor à contaminação e permitir o crescimento de fungos. O objetivo deste estudo foi investigar e identificar as espécies fúngicas presentes em 3 lotes de distintos condimentos provenientes de uma empresa processadora da cidade de Santa Maria (RS). Para as amostras de Cravo-da-índia (Syzygium aromaticum) e Pimentas-do-reino (Piper nigrum) Preta e Branca, utilizouse a técnica de plaqueamento direto após desinfecção em solução de hipoclorito de sódio $0,4 \%$ por 1 minuto. As análises de Pimenta Vermelha (Capsicum annuum), Alecrim (Rosmarinus officinalis), Erva-doce (Foeniculum vulgare), Orégano (Origanum vulgare) e Canela (Cinnamomum zeylanicum) foram feitas através de diluição seriada, seguida de plaqueamento em superfície. As análises foram feitas em triplicata, em meio Dicloran Glicerol 18\% (DG18), com incubação a $25^{\circ} \mathrm{C}$ por 7 dias. Decorrido este período, foi realizado o isolamento e identificação dos fungos seguindo-se as recomendações de meios de cultura e período de incubação de cada gênero. Com exceção do Cravo-da-ìndia, todos os temperos apresentaram intensa presença fúngica, com predominância dos gêneros Aspergillus e Eurotium, e presença de

\footnotetext{
Referência:

Cátia Daiane Scherer, Maria de Jesus Alcano, Évelin Francine Wigmann, Raquel Carine Jahn, Marcelo Valle Garcia, Vivian Moraes Machado, Marina Venturini Copetti.Fungos com Potencial Toxigênico em Condimentos. In: Anais do 12 Congresso Latinoamericano de Microbiologia e Higiene de Alimentos - MICROAL 2014 [= Blucher Food Science Proceedings, num.1, vol.1]. São Paulo: Editora Blucher, 2014. DOI 10.5151/foodsci-microal-052
} 
Penicillium sp., Fusarium sp., Paecilomyces sp., além de zigomicetos e dematiáceos. A freqüência de Aspergillus potencialmente toxigênicos foi intensa nas Pimentas Branca e Preta com presença de A. flavus (até 30\%), A. parasiticus (até 15\%), complexo A. niger (até 33\%) e A. ochraceus (até $15 \%$ ). Também se destaca a alta presença de A. niger em orégano e de Eurotium spp. em erva-doce, alecrim e pimenta vermelha. Os condimentos analisados neste estudo mostraram ampla contaminação por fungos potencialmente produtores de micotoxinas, o que podem constituir um perigo para a saúde dos consumidores. Estudos complementares avaliando a capacidade toxigênica dos isolados e a presença de micotoxinas nas amostras serão conduzidos, bem como será feita uma investigação de medidas a serem adotadas para prevenir a contaminação destes produtos e reduzir o perigo ao consumidor.

Palavras-Chave: Aspergillus, Micotoxina, Pimenta, Tempero Agência de Fomento: Fundação de Amparo à Pesquisa do Estado do Rio Grande do Sul - FAPERGS 